UDC 338.984

LBC 65.054

\title{
METHODOLOGICALASPECTS OF MONITORING IN THE SYSTEM OF INDICATIVE MANAGEMENT OF SOCIAL ORGANIZATIONS
}

\author{
Olga A. Lomovtseva
}

Belgorod State National Research University, Belgorod, Russian Federation

\section{Boris A. Tkhorikov}

Belgorod State National Research University, Belgorod, Russian Federation

\begin{abstract}
To reduce the risks of economic activities of organizations in the public sector of the economy, it is advisable to include the monitoring of the current functioning and forecasting the prospects of organizations' development in the sector, regional, national contexts in the management system.

The implementation of monitoring in the process and system approaches is considered, it is established that the monitoring is integrated into the "monitoring" and "planning" functions, respectively, and the shortcomings of this integration are shown. The process approach is currently used in public administration, and the quality of monitoring cannot be called high. It is proved that for the purposes of indicative management, integration with the organization function is necessary. The evidence base consists in the place of monitoring in the general system of indicative management and its methodological basis, including the concept of monitoring, its object, subject, purposes and functions. The authors reveal the target and structurally functional focus of monitoring has been established in relation to the indicative management of social organizations.
\end{abstract}

Key words: indicative management, social organizations, monitoring, state management of the economy.

УДК 338.984

ББК 65.054

\section{МЕТОДОЛОГИЧЕСКИЕ АСПЕКТЫ РЕАЛИЗАЦИИ МОНИТОРИНГА В СИСТЕМЕ ИНДИКАТИВНОГО УПРАВЛЕНИЯ ОРГАНИЗАЦИЯМИ СОЦИАЛЬНОЙ СФЕРЫ}

\author{
Ольга Алексеевна Ломовцева \\ Белгородский государственный национальный исследовательский университет, \\ г. Белгород, Российская Федерация \\ Борис Александрович Тхориков \\ Белгородский государственный национальный исследовательский университет, \\ г. Белгород, Российская Федерация
}


Аннотация. Для снижения рисков хозяйственной деятельности организаций в общественном секторе экономики в систему управления целесообразно включить мониторинг текущего функционирования и прогнозирование перспектив развития самих организаций в отраслевом, региональном, национальном контекстах. В этой связи в статье рассмотрена реализация мониторинга в процессном и системном подходах и установлена его интегрированность в функции «контроль» и «планирование»; соответственно, показаны недостатки таких подходов. Процессный подход используется в настоящее время в государственном управлении, при этом качество мониторинга нельзя назвать высоким. Доказано, что для целей индикативного управления необходима интеграция с функцией организации (организовывания). Доказательной базой послужили место мониторинга в общей системе индикативного управления и его методологическая основа, в том числе понятия мониторинга, его объект, предмет, цели и функции. Установлена целевая и структурнофункциональная направленность мониторинга применительно к индикативному управлению организациями социальной сферы.

Ключевые слова: индикативное управление, организации социальной сферы, мониторинг, государственное управление экономикой.

Особенности управления организациями отраслей производства общественных благ и услуг (социальной сферы) обусловлены необходимостью сопряженности организационных целей и эффективности с целями и стратегиями общенационального масштаба, приоритетами развития российского государства и общества. При этом сами организации социальной сферы встроены в экономическую сферу общества, характеризуются многофакторностью качества и объемов услуг [5], что существенно повышает риски применения как рыночных, так и государственных регуляторов, неизбежно приводит к социальным асимметриям, росту неэффективных затрат, снижению мотивации отдельных субъектов хозяйствования. Поэтому для управления организациями в общественном секторе экономики необходима гибкая система индикаторов, одновременно определяющая цели деятельности, границы самостоятельности, условия получения ресурсной поддержки, позволяющая проводить мониторинг текущего функционирования и прогнозирование перспектив развития самих организаций, а также в отраслевом, региональном, национальном контекстах.

Попытки решать проблемы достижения баланса интересов государства с социальными и коммерческими целями отдельных организаций социальной сферы с использованием индикативного подхода уже предпринимаются в России в течение последних 15 лет, институционально подкрепляясь все новыми нормативными и законодательными документами, охватывая комплекс планово-программных решений органов власти и управления на разных уровнях [9]. Значимыми в этом кон- тексте являются так называемые майские указы Президента России, принятые в 2012 г., содержащие более 200 поручений Правительству РФ на период 2012-2018 гг., в которых были закреплены ключевые параметры и индикаторы деятельности разных отраслей, в том числе социальной сферы, ставшие императивами деятельности на микро-, мезо- и макроуровнях национальной экономики. С учетом инициативного согласования (по аналогии с балансовым планированием в бывшем СССР) были определены значения индикаторов, достижение которых возможно только за счет координированного и синхронного преобразования в сопряженных отраслях народного хозяйства. Основными исполнителями выступают субъекты РФ, разрабатывающие и утверждающие «дорожные карты» по осуществлению соответствующих действий в социально-экономической сфере. Подобная логика напоминает классическое государственное индикативное планирование начала XX в. в странах Западной Европы, Азии и США [10]. Однако современная теория и практика индикативного управления находится в стадии становления и осмысления, пока слабо институционализирована, не имеет доработанного до операционного уровня методического инструментария, нуждается в систематизации, обобщениях и практических рекомендациях. Одна из сложных проблем системы управления организация мониторинга выполнения и корректировки индикаторов.

Рассмотрим основные проблемы мониторинга в практической деятельности индикативного управления. Основные стратегические цели и задачи государственной политики, 
в том числе социальной, закреплены в 44 государственных программах, сгруппированных по пяти направлениям: «Новое качество жизни», «Инновационное развитие и модернизация экономики», «Обеспечение национальной безопасности», «Сбалансированное региональное развитие» и «Эффективное государство». Основным требованием к системе индикаторов является ограниченность и достаточность их количества, возможность охватить максимально возможное количество процессов и явлений. Анализ состава индикаторов показал, что в государственные программы включено более 2000 таковых, при этом не по всем предусмотрены плановые значения, некоторые не имели фактического значения к моменту составления отчетности, достигнутые значения показателей заметно превышали плановый уровень, используются показатели (индикаторы), не имеющие динамики изменения с течением времени. Кроме того, корректировка параметров (индикаторов) государственных программ проводится зачастую вне связи с финансированием, без учета данных мониторинга, объективной и достоверной оценки результатов, то есть роль мониторинга игнорируется.

Можно говорить также о низком качестве или отсутствии оценки кросс-влияния воздействия основных мероприятий одной государственной программы на иные государственные программы и наоборот. Используемые методы мониторинга не обеспечивают информационную поддержку для управления социальным партнерством субъектов индикативного управления и реализации их индивидуальных целей и интересов, координацию (при необходимости) межотраслевого или межведомственного взаимодействия, требуемого для достижения уникального результата. Таким образом, необеспеченность методологическим наполнением процессов мониторинга в общем контуре индикативного управления негативно влияет на общую эффективность управления.

Термин «мониторинг» начал активно употребляться в менеджменте начиная со второй половины XX века. Одно из первых его определений предложил отечественный экономист А. Никонов: «...мониторинг - это совокупность приемов по отслеживанию, анализу, оценке и прогнозированию социально-экономических процессов, связанных с реформами, а также сбор, обработка информации и подготовка рекомендаций по развитию реформы...» [21]. Данное определение и сейчас актуально отражает содержательную часть мониторинга в менеджменте - наблюдение, оценка, анализ и прогнозирование состояния различных процессов. Анализ работ Н. Бурмистрова, Р. Еремина, Г. Кутергиной, И. Рисина, А. Соколова, Л. Цзинь-Вэнь показывает, что дискуссионными остаются его организация, взаимосвязь с функциями менеджмента и цели (задачи) мониторинга (см.: [4; 7; 8; 11; 13; 16; $17 ; 23])$.

Процедуры мониторинга сопоставляют цели с фактическими характеристиками изучаемого объекта и выявляют их соответствие определенным ориентирам, дабы обеспечить информацией процессы принятия управленческих решений. Следовательно, мониторингом предусмотрен целый комплекс действий (регистрация необходимых характеристик состояния и динамики изменения объекта управления на основе наблюдения, анализ, диагностика, оценка и прогнозирование для определения тенденций, возможностей или угроз внешней и внутренней среды), при помощи которого субъекты управления обеспечиваются своевременной, необходимой, достаточной и достоверной информацией. Именно мониторинг является связующим звеном в трансформации концептуальных представлений о целях в конкретные задачи.

В научной литературе мониторинг рассматривается с процессной или системной точки зрения, это влияет на его восприятие в системе управления и ключевые задачи.

Процессный подход рассматривает управление как непрерывную серию последовательных, взаимосвязанных управленческих функций, мониторинг социально-экономических систем чаще представляют элементом контроля основных параметров (индикаторов) деятельности объектов управления, то есть ставят в окончание цикла. В качестве элементов самого мониторинга выделяют наблюдение, сбор (обработку) и анализ данных.

Мониторинг обеспечивает перманентное наблюдение за объектом управления, фиксирует его заданные характеристики, готовит 
шаблоны оценок и в режиме, близком к реальному времени, выявляет результаты воздействия различных факторов внешней и внутренней среды. С его помощью можно также осуществлять наблюдение, оценку, прогноз состояния отдельного явления (процесса), специально выбранного субъектом управления.

Основная цель мониторинга в процессном подходе - сравнение фактического состояния объекта управления по заданным индикаторам с плановыми значениями и сопоставление возможных отклонений с допустимым критическим уровнем для своевременной реализации превентивных мероприятий и сохранения стабильного функционирования. Мониторинг в большей степени интегрирован с функцией контроля и его приоритетными задачами: 1) изучение фактического состояния и динамики развития объекта мониторинга, в том числе по его структурным элементам и направлениям деятельности; 2) контроль и оценка социально-экономических процессов.

Процессный подход используется в настоящее время в государственном управлении, при этом качество мониторинга нельзя назвать высоким. На это указывают безуспешные попытки проведения мониторинга выполнения государственных программ. Корректно отследить изменения большого числа показателей крайне трудно, в том числе из-за того, что данные Росстата и отраслевой статистики не охватывают такого количества параметров. Счетная палата Российской Федерации для повышения качества мониторинга выступает за резкое сокращение количества показателей: должны быть показатели, по которым есть официальная статистка; эти показатели должны характеризовать именно деятельность соответствующей отрасли; показатели должны отражать изменения в организациях, а не использоваться просто для их вычисления.

В системном подходе, как отмечают К. Алдаров и Т. Сорокина, воспринимающем организацию как совокупность взаимосвязанных элементов, содержание мониторинга значительно расширяется $[1 ; 18]$. К задачам мониторинга добавляются планирование, регулирование и прогнозирование, которые совместно с учетом, контролем и анализом образуют комплекс функций управления.
Из работ А. Бондарева, О. Урбанаева, Ю. Шишаковой, К. Шишакова следует, что основная цель мониторинга в системном подходе - оперативное управление развитием объекта, так как мониторинг включает в себя функцию планирования [2;19;20], с которой он более всего интегрирован. Ключевыми задачами мониторинга выступают: 1) выявление факторов, определяющих негативные тенденции, определение проблемных зон и точек роста социально-экономических систем; 2) разработка прогнозов и сценариев развития объекта управления с учетом ожидаемых последствий и рисков; 3) обоснование мероприятий, направленных на упреждение потенциальных угроз, преодоление отрицательных и стимулирование перспективных тенденций развития объекта управления.

Рассмотренные варианты интеграции мониторинга с функциями контроля или планирования не соответствуют индикативному подходу к управлению организациями социальной сферы (OCC), так как контроль осуществляется главным образом за итоговыми значениями индикаторов, а планирование в системе индикативного управления проводится преимущественно на основании стратегических и согласованных целей стейкхолдеров, воспринимающих текущие показатели работы ОСС как условия для перспективной работы, не всегда требующей преемственности с ранее выбранным курсом развития.

Понимание сущности мониторинга позволяет ответить на важный теоретический вопрос - место социально-экономического мониторинга в системе управления. По-видимому, в данном случае следует говорить о том, что за счет мониторинга возникает замкнутый цикл управления, в котором он становится не просто частью действий (функции) по организации достижения целей, приобретает самостоятельное значение во вложенной структуре функций (см. табл. 1), своего рода, функция в функции. Это обеспечивает, учитывая специфику индикативного управления в части организационной свободы субъекта в выборе средств и методов достижения заданных значений целевых индикаторов, постоянное наблюдение за промежуточными результатами деятельности и необходимый запас времени для оперативной корректировки в случае прогнозирования возникновения критических отклонений. 


\section{Сравнение функций управления организациями социальной сферы в различных концептуальных подходах менеджмента}

\begin{tabular}{|c|c|c|}
\hline $\begin{array}{c}\text { Наименование } \\
\text { функции }\end{array}$ & $\begin{array}{c}\text { Содержание в неоклассической } \\
\text { теории }\end{array}$ & Содержание в индикативном управлении \\
\hline Планирование & $\begin{array}{l}\text { - ориентация организации на } \\
\text { собственные цели деятельно- } \\
\text { сти; } \\
\text { - интуитивное целеполагание, } \\
\text { основанное на попытках пред- } \\
\text { видеть рыночные тренды; } \\
\text { - резервирование ресурсов для } \\
\text { конкурентной борьбы; } \\
\text { - перманентный поиск досту- } \\
\text { па к новым источникам фи- } \\
\text { нансирования } \\
\end{array}$ & $\begin{array}{l}\text { - ориентация деятельности организации на стратегические } \\
\text { цели социальной сферы; } \\
\text { - постановка целей текущей деятельности на основании } \\
\text { согласованных прогнозов развития внешней среды; } \\
\text { - минимизация ресурсных затрат на ведение конкурентной } \\
\text { борьбы; } \\
\text { - гарантированный доступ к источникам государственного } \\
\text { финансирования при соблюдении заданных условий дея- } \\
\text { тельности; } \\
\text { - разработка мероприятий по достижению целей с предло- } \\
\text { жением методов-регуляторов по их достижению }\end{array}$ \\
\hline \multirow[t]{4}{*}{ Организация } & \multirow{4}{*}{$\begin{array}{l}\text { - построение организацион- } \\
\text { ной структуры с учетом ми- } \\
\text { нимизации текущих затрат; } \\
\text { - распределение задач, пол- } \\
\text { номочий, ответственности и } \\
\text { ресурсов, преимущественно, } \\
\text { между собственными испол- } \\
\text { нителями и обеспечение их } \\
\text { совместной работы; } \\
\text { - создание замкнутой согласо- } \\
\text { ванности действий структур- } \\
\text { ных подразделений; } \\
\text { - акцентированное поддержа- } \\
\text { ние устоявшегося режима ра- } \\
\text { боты; } \\
\text { - преобладание межличност- } \\
\text { ных отношений при построе- } \\
\text { нии и осуществлении бизнес- } \\
\text { процессов }\end{array}$} & $\begin{array}{l}\text { Организация } \\
\text { - построение организационной структуры с учетом наиболее } \\
\text { эффективной реализации значений целевых индикаторов; } \\
\text { - распределение задач с учетом анализа текущей эффек- } \\
\text { тивности деятельности различных субъектов управления }\end{array}$ \\
\hline & & $\begin{array}{l}\text { Мотивация } \\
\text { - ориентация на достижение синергетического эффекта от } \\
\text { взаимодействия со всеми заинтересованными экономиче- } \\
\text { скими субъектами }\end{array}$ \\
\hline & & $\begin{array}{l}\text { Мониторинг } \\
\text { - формирование информационной базы для реализации } \\
\text { функции регулирования и прогнозирования развития, обес- } \\
\text { печение оперативного принятия управленческих решений }\end{array}$ \\
\hline & & $\begin{array}{l}\text { Координация } \\
\text { - построение взаимодействия со структурными подразде- } \\
\text { лениями с использованием автоматизированной системы } \\
\text { управления; } \\
\text { - минимизации межличностных отношений за счет уста- } \\
\text { новления единых (объективных) индикаторов деятельности }\end{array}$ \\
\hline Мотивация & $\begin{array}{l}\text { - ориентация на внутреннюю } \\
\text { среду организации, в том чис- } \\
\text { ле активизация деятельности } \\
\text { персонала и побуждение его к } \\
\text { эффективному труду для дос- } \\
\text { тижения целей организации } \\
\end{array}$ & - \\
\hline Контроль & $\begin{array}{l}\text { - ретроспективная оценка } \\
\text { достигнутых и запланирован- } \\
\text { ных результатов на основе ус- } \\
\text { тановленных стандартов; } \\
\text { - односторонняя корректи- } \\
\text { ровка целей в случае серьез- } \\
\text { ных отклонений от первона- } \\
\text { чального плана }\end{array}$ & $\begin{array}{l}\text { Регулирование } \\
\text { - текущая оценка деятельности и оперативная корректи- } \\
\text { ровка на основании результатов постоянного мониторинга; } \\
\text { - применение методов-регуляторов в случае отклонений; } \\
\text { - согласованная корректировка целей в случае значитель- } \\
\text { ных отклонений от целевых значений индикаторов боль- } \\
\text { шинства субъектов управления или получение временной } \\
\text { дотационной поддержки со стороны стейкхолдеров; } \\
\text { - разработка программы развития отдельной организации } \\
\text { при необходимости осуществления регулирующих меро- } \\
\text { приятий на микроуровне }\end{array}$ \\
\hline
\end{tabular}

Примечание. Составлено авторами.

Гибкость и динамичность индикативного управления позволяют перейти от «контрольной» основы мониторинга, ориентированной на использование ретроспективной информации, к «организационной»- обеспечивающей, по мнению В. Шлейникова, своевременное принятие оперативных управленческих решений при возникновении риска отклонения от заданных значений индикаторов [22]. Так, для определенных показателей можно установить тен- 
денции, прогнозирующие их значение в будущем, и заблаговременно определить состояние системы, вместо использования «запаздывающих характеристик» для ее смещения в более стабильное состояние [26]. Организация работы по достаточному числу индикаторов приведет к снижению общей степени неопределенности управления. В данном случае неопределенность отдельных параметров работы сохранится, но уменьшится общая неопределенность функционирования ОСС.

На основании вышеизложенного можно говорить о том, что в системе индикативного управления мониторинг переходит из объективно-пассивной позиции в субъектно-активную. В традиционном менеджменте (например, системный или процессный подход) мониторинг не предполагает вмешательства субъекта управления, он является специально организованным, систематическим наблюдением за объектом с целью его оценки. В индикативном управлении мониторинг может рассматриваться как информационное обеспечение процесса принятия управленческих решений, в том числе оптимизирующих условия, детерминирующие функционирование и развитие объекта. Применительно к ОСС мониторинг имеет активный характер, так как предполагает создание информационной базы для управления. Это подтверждается также тем, что в деятельности ОСС существуют положительные и отрицательные тенденции, которые недостаточно только выявить и классифицировать. В процессе проведения мониторинга, используя обобщенную информацию, возможно сформировать представление о состоянии и динамике развития ОСС, необходимое для принятия управленческих решений, позволяющих ограничить или полностью нейтрализовать отрицательное воздействие и усилить действие благоприятных факторов и условий $[6 ; 13 ; 25]$.

Интеграция мониторинга с функцией организации позволит повысить эффективность деятельности за счет сокращения времени на реализацию превентивных воздействий. Для ОСС можно выделить группы типовых причин отклонений от индикативных плановых значений как на уровне организации, так и ее структурных подразделений. Важным моментом является выработка типовых протоколов управ- ленческих действий в случае проявления негативных факторов. Для этого факторы или причины должны быть формализованы и фактически приниматься во внимание руководством OCC, так как зачастую менеджмент организации социальной сферы скрывает внутренние проблемы или не обращает на них внимания, несмотря на то что они являются очевидными, объективными и поддаются устранению при должном внимании.

При изменении значений индикаторов и отклонениях в работе от стратегических целей индикаторы предотвратят уход ОСС с целевой траектории с помощью условных агентов управления, способных в автоматизированном режиме предлагать рекомендации или самостоятельно принимать решения в рамках заданной компетенции, в том числе, как пишет У. Эккерсон, реагируя на изменения в рутинных событиях [24]. В подобном случае мониторинг может выполнять отчасти и роль контроллинга. Используя различные наборы значений индикаторов, субъект управления может выбирать наиболее оптимальные решения из имеющихся шаблонов и изменять локальные состояния ОСС для достижения общего баланса.

Предложенный подход к мониторингу ОСС как элемента вложенной структуры функции организации позволяет представить его целевую и структурно-функциональную направленность:

- мониторинг направлен на непрерывную диагностику текущего состояния ОСС и выявление возможных тенденций ее развития, подготовку информационной базы для принятия управленческих решений, обеспечение эффективности работы, достоверность используемой отчетности, соблюдение действующего законодательства и иных требований, установленных субъектом мониторинга;

- цели мониторинга реализуются в целом на уровне ОСС, отдельных направлений ее деятельности (например, снабжение, оказание социальных услуг, обучение персонала и пр.) или структурных подразделений.

С учетом изложенного выше, а также некоторых идей, отраженных в работах А. Брякиной [3], М. Осиповой, О. Буториной [12], Н. Сироткиной [14; 15], опринципах индикативного управления для производственных пред- 
приятий, определим содержание мониторинга, проведем группировку и состав принципов реализации мониторинга в системе индикативного управления ОСС (табл. 2).

Мониторинг - это непрерывная и регламентированная деятельность субъектов управления ОСС по созданию и анализу стандартизированной информации о состоянии объектов управления по заданным индикаторам, а также оценка текущего функционирования и перспективных результатов, обоснование управленческих решений по их корректировке.

Цель мониторинга - комплексная оценка возможности достижения заданных результатов с помощью количественной (качествен-

\section{Группировка и состав принципов реализации мониторинга в системе индикативного управления ОСС}

\begin{tabular}{|c|c|}
\hline $\begin{array}{c}\text { Группировка } \\
\text { принципов }\end{array}$ & Принципы \\
\hline $\begin{array}{l}\text { Кластер } 1 \text { - } \\
\text { общееоргани- } \\
\text { зациионные }\end{array}$ & $\begin{array}{l}\text { - целенаправленность - выбор подходов, инструментария и параметров наблюдения в } \\
\text { соответствии с заданными функцией планирования целями деятельности организации; } \\
\text { - системность - требует периодичности и достаточности наблюдений за состоянием всей } \\
\text { совокупности объектов при соблюдении условий индивидуальности получаемых резуль- } \\
\text { татов по анализу состояния каждого из них; } \\
\text { - согласованность - результаты мониторинга должны быть применимы в практической } \\
\text { работе различными структурными подразделениями объекта управления и заинтересо- } \\
\text { ванными внешними стейкхолдерами; } \\
\text { - изменяемость - возможность дополнения, сокращения, модификации системы монито- } \\
\text { ринга при изменении внешней среды }\end{array}$ \\
\hline $\begin{array}{l}\text { Кластер } 2 \text { - } \\
\text { методические }\end{array}$ & $\begin{array}{l}\text { - релевантность и транспарентность информации - доступность всесторонних данных о } \\
\text { состоянии объекта мониторинга, а также возможность представления информации орга- } \\
\text { нам управления и другим стейкхолдерам; } \\
\text { - эмерджентность - изменение отдельных индикаторов не означает изменения свойств } \\
\text { всей социально-экономической системы; } \\
\text { - полнота и достаточность нормативного обеспечения проектирования, разработки и } \\
\text { внедрения системы мониторинга, начиная от актов, регламентирующих содержание, це- } \\
\text { ли и задачи мониторинга по уровням объекта управления, до правил подтверждения и } \\
\text { учета в работе результатов мониторинга }\end{array}$ \\
\hline $\begin{array}{l}\text { Кластер } 3 \text { - } \\
\text { технологические }\end{array}$ & $\begin{array}{l}\text { - обоснованность выделения объектов мониторинга - определяется по результатам ана- } \\
\text { лиза приоритетных направлений развития объекта управления и рационального исполь- } \\
\text { зования всех видов ресурсов; } \\
\text { - интегративность и дифференцируемость информации - возможность квалитативного } \\
\text { анализа сопоставимых показателей о состоянии объекта мониторинга или его элементов; } \\
\text { - оперативность и непрерывность сбора информации - анализ состояния осуществляется } \\
\text { путем сравнения базовых (исходных) данных с данными, полученными в результате ис- } \\
\text { следований, что требует систематического пополнения базы данных из статистической } \\
\text { отчетности, информации участников мониторинга, оперативных показателей, фикси- } \\
\text { рующих актуальные изменения; } \\
\text { - информационная компетентность исполнителей, обеспечение необходимыми и доста- } \\
\text { точными информационными и другими материалами для эффективного мониторинга }\end{array}$ \\
\hline $\begin{array}{l}\text { Кластер } 4 \text { - } \\
\text { результативно- } \\
\text { оценочные }\end{array}$ & $\begin{array}{l}\text { - социальная направленность - приоритет общественных интересов при оценке и кор- } \\
\text { рекции работы ОСС по итогам мониторинга, недопущение реализации сценариев, спо- } \\
\text { собных привести к снижению качества жизни населения; } \\
\text { - достоверность выводов по результатам мониторинга, включая информацию об эффек- } \\
\text { тивности управления, прогнозах и тенденциях развития с целью выработки рекоменда- } \\
\text { ций по предупреждению и преодолению негативных процессов на различных уровнях } \\
\text { объекта мониторинга; } \\
\text { - моделируемость, построение прогнозных моделей развития объекта управления, пред- } \\
\text { ставление руководству организаций прогнозов и рекомендации по корректировке дея- } \\
\text { тельности; } \\
\text { - применимость результатов мониторинга, открытое заинтересованное их обсуждение, } \\
\text { внедрение корректив в деятельность ОСС, обновление и сохранность информации }\end{array}$ \\
\hline
\end{tabular}

Примечание. Составлено авторами. 
ной) характеристики соответствующих индикаторов и подготовка информации для принятия управленческих решений.

Объект мониторинга - внутренние социально-экономические процессы организаций социальной сферы.

Предмет мониторинга - параметры работы организаций социальной сферы по установленным индикаторам и их целевым значениям.

Указанные принципы обусловливают необходимость и требуют обязательного выполнения таких основных процедур, как обособление и обследование ОСС, составление информационной параметрической модели ОСС и ее идентификация, планирование и прогнозирование измерений в состоянии ОСС, представление информации в удобной для пользователя форме.
В соответствии с описанными представлениями о сущности мониторинга в системе индикативного управления предложим соответствующий набор функций и субфункций мониторинга, которые охватывают собой весь цикл (табл. 3).

В заключение необходимо сказать, что для некоммерческих организаций социальной сферы применяется традиционная система оценки эффективности деятельности (статистический подход), основанная на ретроспективном измерении объемов расхода ресурсов, себестоимости оказываемых услуг, показателей прибыльности или иных специализированных показателей отраслевой статистики. Подобная практика эффективна для краткосрочного периода и ограничивается условием статичной структуры контрагентов, исключая возможность асимметрии информации и проявления

\section{Взаимосвязь этапов, функций и субфункций мониторинга В индикативном управлении}

\begin{tabular}{|c|c|c|}
\hline $\begin{array}{c}\text { Этапы процесса } \\
\text { индикативного } \\
\text { управления } \\
\end{array}$ & Функция мониторинга & Субфункции мониторинга \\
\hline $\begin{array}{l}\text { Этап I «Форму- } \\
\text { лировка и оценка } \\
\text { целей» }\end{array}$ & $\begin{array}{l}\text { Системная функция - обеспечение в про- } \\
\text { цессе сбора информации внутренней кон- } \\
\text { солидации элементов (структурных под- } \\
\text { разделений) объекта управления и вовлече- } \\
\text { ние всех заинтересованных субъектов в } \\
\text { процессы управления ОСС }\end{array}$ & $\begin{array}{l}\text { - методологическая - определяет концеп- } \\
\text { цию мониторинга как системы, характери- } \\
\text { зует актуальность процессов и обусловлива- } \\
\text { ет необходимость в получении результатов; } \\
\text { - идентификационная - позволяет сопоста- } \\
\text { вить цели исполнителей и руководителей } \\
\text { ОСС с возможностями мониторинга как це- } \\
\text { лостной системы; } \\
\text { - композиционная - отражает иерархиче- } \\
\text { скую соподчиненность целей мониторинга в } \\
\text { ОСС и ее структурных подразделениях }\end{array}$ \\
\hline $\begin{array}{l}\text { Этап II «Разра- } \\
\text { ботка и экспер- } \\
\text { тиза индикато- } \\
\text { ров» }\end{array}$ & $\begin{array}{l}\text { Акмеологическая функция - сбор и обобще- } \\
\text { ние первичной информации, генерация из } \\
\text { базы данных мониторинга отчетных мате- } \\
\text { риалов }\end{array}$ & $\begin{array}{l}\text { - когнитивная - имеет координирующий } \\
\text { характер и направлена на анализ комплекса } \\
\text { условий и ресурсов, а также поиск возмож- } \\
\text { ных альтернативных направлений органи- } \\
\text { зации, функционирования и информацион- } \\
\text { ного сопровождения мониторинга; } \\
\text { - мотивационная - направлена на повыше- } \\
\text { ние активности исполнителей, побуждение } \\
\text { к эффективной работе }\end{array}$ \\
\hline $\begin{array}{l}\text { Этап III «Орга- } \\
\text { низация и прове- } \\
\text { дение монито- } \\
\text { ринга» }\end{array}$ & $\begin{array}{l}\text { Операционная функция - обеспечение ру- } \\
\text { ководителей ОСС и иных пользователей } \\
\text { результатами мониторинга, информацией о } \\
\text { состоянии объекта управления и его эле- } \\
\text { ментов, необходимой для оценки эффек- } \\
\text { тивности текущей работы, принятия опера- } \\
\text { тивных управленческих решений, прогно- } \\
\text { зирования сценариев дальнейшего развития } \\
\text { и координации общего управления }\end{array}$ & $\begin{array}{l}\text { - технологическая - определяет технологии } \\
\text { проектирования, разработки и реализации } \\
\text { системы мониторинга, а также регламент } \\
\text { представления получаемых результатов; } \\
\text { - преобразующая - оптимизирует систему } \\
\text { мониторинга, обеспечивает его ориентацию } \\
\text { на изменения и/или инновации }\end{array}$ \\
\hline
\end{tabular}

Примечание. Составлено авторами. 
рефлексии. Влияние на объект управления внешней среды характеризуется высоким уровнем сложности, динамизма и неопределенности, что приводит к снижению эффективности принятых ранее оптимальных решений и усложнению принятия новых управленческих решений. Возможность преодоления указанной проблемы обеспечивает качественная, своевременная диагностика и оценка эффективности внутренних и внешних процессов организации, которая может быть реализована на основе предложенной авторами методологии мониторинга ОСС. Мониторинг не подменяет собой всю систему управления, но составляет основу для выводов и принятия обоснованных решений. Мониторинг в индикативном управлении устанавливает нормативы и операционализирует их по индикаторам, определяет критерии оценочной деятельности, осуществляет сбор, накопление, систематизацию и анализ данных о состоянии ОСС, причинах наблюдаемых изменений и факторах, их детерминирующих.

\section{СПИСОК ЛИТЕРАТУРЫ}

1. Алдаров, К. Р. Методическое обеспечение стратегического мониторинга потенциала регионального отраслевого комплекса / К. Р. Алдаров // Экономика строительства. - 2010. - № 3. - С. 21-23.

2. Бондарев, А. Е. Мониторинг социальноэкономического развития региона / А. Е. Бондарев // Регион: экономика и социология. - 2010. - № 4. C. $187-202$.

3. Брякина, А. В. Инструменты и методы индикативного управления предприятиями пищевой промышленности : дис. ... канд. экон. наук : 38.00 .05 / Брякина Анастасия Владимировна. - Воронеж, 2013. $-219 \mathrm{c}$.

4. Бурмистров, Н. А. Системный подход к мониторингу развития отрасли / Н. А. Бурмистров // Вестник Саратовского государственного социально-экономического университета. - 2011. - № 1. C. $47-49$.

5. Буянова, М. Э. Государственное регулирование согласования интересов субъектов региональной экономики / М. Э. Буянова // Власть. 2013. -№ 3. - C. 47-50.

6. Воробьев, С. Н. Методы моделирования процесса принятия решения в сложных системах / С. Н. Воробьев // Электронное моделирование. - 1994. - № 5. - С. 22-34.

7. Еремин, Р. В. Особенности проведения мониторинга социально-экономического развития ре- гиона для различных групп пользователей / Р. В. Еремин // Управление экономическими системами. 2011. - № 28. - С. 110-116. - Электрон. текстовые дан. Режим доступа: http://uecs.ru/regionalnaya-ekonomika/ item/412-2011-04-25-10-11-55 (дата обращения: 16.08.2016). - Загл. с экрана.

8. Кутергина, Г. В. Мониторинг потенциальных возможностей саморазвития промышленного предприятия на основе качественных критериев / Г. В. Кутергина // Специалист XXI века: экономическое образование в обеспечении устойчивого развития человеческого потенциала : сб. материалов Рос. науч.-практ. конф. с междунар. участием, посвящ. 65-летию каф. экономики ПГГПУ, Пермь, 20-21 нояб. 2012 г. / Перм. гос. гуманит.-пед. ун-т ; гл. ред. А. М. Белавин. - Пермь, 2012. - С. 136-146.

9. Макаренко, О. С. Структура и перспективы развития государственного сектора экономики / О. С. Макаренко // Вестник Волгоградского государственного университета. Серия 3, Экономика. Экология. - 2016. - № 1. - С. 115-122.

10. Морозова, Н. И. Индикативное планирование: теоретический и практический опыт развитых стран / Н. И. Морозова // Управление экономическими системами. - 2011. - № 4. - Электрон. текстовые дан. - Режим доступа: http://www.uecs.ru/uecs-28282011/item/402-2011-04-25-08-47-52. - Загл. с экрана.

11. Муратова, Л. В. Содержание и функции сбалансированного индикативного менеджмента / Л. В. Муратова // Научный журнал КубГАУ. 2014. - № 4. - C. 1-24.

12. Осипова, М. Ю. Теоретические основы индикативного управления экономическим развитием / М. Ю. Осипова, О. В. Бугорина // Вестник Пермского национального исследовательского политехнического университета. Социально-экономические науки. - 2014. - № 3. - С. 116-123.

13. Рисин, И. Е. Принципы мониторинга социально-экономического развития региона / И. Е. Рисин, И. А. Шлеките // Актуальные проблемы развития территорий и систем регионального и муниципального управления : материалы Междунар. науч.практ. конф., г. Воронеж, 21 окт. 2006 г. / Муницип. акад. Рос. Федерации, Воронеж. гос. ун-т ; под ред. И. Е. Рисина, Ю. И. Трещевского. - Воронеж, 2007. Вып. 3. - С. 29-32.

14. Сироткина, Н. В. Перспективы использования индикативного управления при прогнозировании параметров развития интегрированных формирований / Н. В. Сироткина, С. И. Карпачев // Социальная политика и социология. -2010 . - № 10. С. $190-196$.

15. Сироткина, Н. В. Система индикаторов управления / Н. В. Сироткина, А. А. Черникова, А. В. Попов // Инновационный вестник Регион. 2008. - № 1. - C. 30-32. 
16. Смирнов, Д. Е. Сущность мониторинга качества управления предприятием / Д. Е. Смирнов // Вестник университета Российской академии образования. - 2010. - № 5. - С. 147-149.

17. Соколов, А. В. Форсайт: взгляд в будущее / А. В. Соколов // Форсайт. - 2007. - Т. 1, № 1.- С. 8-15.

18. Сорокина, Т. В. Мониторинг качества бюджетного процесса в регионе (на примере Иркутской области) / Т. В. Сорокина // Известия Иркутской государственной экономической академии. 2011. - № 3 (77). - С. 31-35.

19. Урбанаев, О. Л. Система регионального экономического мониторинга: экономическая сущность, принципы и направления формирования / О. Л. Урбанаев // Вестник Бурятского государственного университета. - 2010. - № 2. - С. 52-54.

20. Шишакова, Ю. В. Построение системы антикризисного мониторинга промышленного комплекса региона / Ю. В. Шишакова, К. В. Шишаков // Проблемы региональной экономики. - 2009. № 3/4. - С. 130-138.

21. Шишкин, А. И. Сущность, задачи и принципы мониторинга социально-экономических процессов в регионе / А. И. Шишкин // Экономика Северо-Запада: проблемы и перспективы развития. 2004. - № 1 (19). - С. 16-30. - (Рабочее совещание «Экономический рост в регионах России», г. СанктПетербург, 17 марта 2003 г.).

22. Шлейников, В. И. Финансовый контроль и аудит: от прошлого к будущему (философия (контуры будущего) финансового контроля в России) / В. И. Шлейников // Аудит и финансовый анализ. 2007. - № 1. - С. 6-25.

23. Шувалова, Ю. Ю. Совершенствование мониторинга социально-экономического развития региона : автореф. дис. ... канд. экон. наук : 08.00.05 / Шувалова Юлия Юрьевна. - СПб., 2012. - 21 с.

24. Эккерсон, У. У. Панели индикаторов как инструмент управления: ключевые показатели эффективности, мониторинг деятельности, оценка результатов / У. У. Эккерсон ; [пер. с англ. А. Сатунин]. М. : АльпинаБизнесБукс, 2007. - 395 с.

25. Helfert, E. A. Financialanalysis: toolsandtechniques: aguideformanagers / E. A. Helfert. N. Y. : McGraw-Hill, 2001.-485 p.

26. Wasson, C. S. System analysis, design, and development: concepts, principles, and practices / C. S. Wasson. - Hoboken, N. J. : Wiley-Interscience, 2005. -818 p.

\section{REFERENCES}

1. Aldarov K.R. Metodicheskoe obespechenie strategicheskogo monitoringa potentsiala regionalnogo otraslevogo kompleksa [Methodological
Support of Strategic Monitoring of the Potential of Regional Industrial Complex]. Ekonomika stroitelstva, 2010, no. 3, pp. 21-23.

2. Bondarev A.E. Monitoring sotsialnoekonomicheskogo razvitiya regiona [Monitoring of the Socio-Economic Development of the Region]. Region: ehkonomika i sotsiologiya, 2010, no. 4, pp. 187-202.

3. Bryakina A.V. Instrumenty $i$ metody indikativnogo upravleniya predpriyatiyami pishchevoy promyshlennosti: dis. ... kand. ekon. nauk [Tools and Methods of Indicative Management of Food Industry Enterprises. Cand. econ. sci. diss.]. Voronezh, 2013.219p.

4. Burmistrov N.A. Sistemnyy podkhod k monitoringu razvitiya otrasli [System Approach to Monitoring the Industry Development]. Vestnik Saratovskogo gosudarstvennogo sotsialnoekonomicheskogo universiteta, 2011, no. 1, pp. 47-49.

5. Buyanova M.E. Gosudarstvennoe regulirovanie soglasovaniya interesov subyektov regionalnoy ekonomiki [State Regulation of Coordinating the Interests of Regional Economy Subjects]. Vlast, 2013, no. 3. pp. 47-50.

6. Vorobyev S.N. Metody modelirovaniya protsessa prinyatiya resheniya $\mathrm{v}$ slozhnykh sistemakh [Methods for Modeling Decision-Making in Complex Systems]. Elektronnoe modelirovanie, 1994, no. 5, pp. 22-34.

7. Eremin R.V. Osobennosti provedeniya monitoringa sotsialno-ekonomicheskogo razvitiya regiona dlya razlichnykh grupp polzovateley [Features of Monitoring Social and Economic Development of the Region for Different Groups of Users]. Upravlenie ekonomicheskimi sistemami, 2011, no. 28, pp. 110-116. URL: http://uecs.ru/regionalnaya-ekonomika/item/4122011-04-25-10-11-55. (accessed August 16, 2016).

8. Kutergina G.V. Monitoring potentsialnykh vozmozhnostey samorazvitiya promyshlennogo predpriyatiya na osnove kachestvennykh kriteriev [Monitoring of Potential Opportunities for SelfDevelopment of an Industrial Enterprise on the Basis of Qualitative Criteria]. Belavin A.M. ed. Spetsialist XXI veka: ekonomicheskoe obrazovanie $v$ obespechenii ustoychivogo razvitiya chelovecheskogo potentsiala: sb. materialov Ros. nauch.-prakt. konf. s mezhdunar. uchastiem, posvyashch. 65-letiyu kaf. ekonomiki PGGPU, Perm, 20-21 noyab. $2012 \mathrm{~g}$. [Specialist of the $21^{\text {st }}$ Century: Economic Education in Ensuring Sustainable Development of Human Potential: Collected Materials of Russian Scientific-Practical Conference with International Participation Dedicated to the $65^{\text {th }}$ Anniversary of the Department of Economics of PSPU, Perm, November 20-21, 2012]. Perm, 2012, pp. 136-146.

9. Makarenko O.S. Struktura i perspektivy razvitiya gosudarstvennogo sektora ekonomiki 
[Structure and Prospects of Development of Public Sector of the Economy]. Vestnik Volgogradskogo gosudarstvennogo universiteta. Seriya 3, Ekonomika. Ekologiya [Science Journal of Volgograd State University. Global Economic Systsem], 2016, no. 1, pp. 115-122.

10. Morozova N.I. Indikativnoe planirovanie: teoreticheskiy i prakticheskiy opyt razvitykh stran [Indicative Planning: Theoretical and Practical Experience of Developed Countries]. Upravlenie ekonomicheskimi sistemami, 2011, no. 4. URL: http:/ /www.uecs.ru/uecs-28-282011/item/402-2011-04-2508-47-52.

11. Muratova L.V. Soderzhanie i funktsii sbalansirovannogo indikativnogo menedzhmenta [The Content and Functions of Balanced Indicative Management]. Nauchnyy zhurnal KubGAU, 2014, no. 4, pp. 1-24.

12. Osipova M.Yu., Butorina O.V. Teoreticheskie osnovy indikativnogo upravleniya ekonomicheskim razvitiem [Theoretical Bases of Indicative Management of Economic Development]. Vestnik Permskogo natsionalnogo issledovatelskogo politekhnicheskogo universiteta. Sotsialno-ekonomicheskie nauki, 2014, no. 3, pp. 116-123.

13. Risin I.E., Shlekite I.A. Printsipy monitoringa sotsialno-ekonomicheskogo razvitiya regiona [Principles for Monitoring the Socio-Economic Development of the Region]. Risin I.E., Treshchevsky Yu.I., eds. Aktualnye problemy razvitiya territoriy $i$ sistem regionalnogo i munitsipalnogo upravleniya: materialy Mezhdunar. nauch.-prakt. konf., g. Voronezh, 21 okt. 2006 g. [Relevant Problems of Territorial Development and Systems of Regional and Municipal Management: Materials of International Scientific-Practical Conference, Voronezh, October 21, 2006]. Voronezh, 2007, iss. 3, pp. 29-32.

14. Sirotkina N.V., Karpachev S.I. Perspektivy ispolzovaniya indikativnogo upravleniya pri prognozirovanii parametrov razvitiya integrirovannykh formirovaniy [Prospects of Using Indicative Management in Forecasting the Parameters of Integrated Formation Development]. Sotsialnaya politika i sotsiologiya, 2010, no. 10, pp. 190-196.

15. Sirotkina N.V., Chernikova A.A., Popov A.V. Sistema indikatorov upravleniya [System of Management Indicators]. Innovatsionnyy vestnik Region, 2008, no. 1, pp. 30-32.

16. Smirnov D.E. Sushchnost monitoringa kachestva upravleniya predpriyatiem [The Essence of Monitoring the Quality of Enterprise Management]. Vestnik universiteta Rossiyskoy akademii obrazovaniya, 2010, no. 5, pp. 147-149.
17. Sokolov A.V. Forsayt: vzglyad v budushchee [Foresight: a Look into the Future]. Forsajt, 2007, vol. 1, no. 1, pp. 8-15.

18. Sorokina T.V. Monitoring kachestva byudzhetnogo protsessa $\mathrm{v}$ regione (na primere Irkutskoy oblasti) [Monitoring of the Quality of the Budget Process in the Region (the Case of the Irkutsk Region)]. Izvestiya Irkutskoy gosudarstvennoy ekonomicheskoy akademii, 2011, no. 3 (77), pp. 31-35.

19. Urbanaev O.L. Sistema regionalnogo ekonomicheskogo monitoringa: ekonomicheskaya sushchnost, printsipy i napravleniya formirovaniya [The System of Regional Economic Monitoring: Economic Essence, Principles and Directions of Formation]. Vestnik Buryatskogo gosudarstvennogo universiteta, 2010, no. 2, pp. 52-54.

20. Shishakova Yu.V., Shishakov K.V. Postroenie sistemy antikrizisnogo monitoringa promyshlennogo kompleksa regiona [Construction of the System of Anti-Crisis Monitoring of the Industrial Complex of the Region]. Problemy regionalnoy ekonomiki, 2009, no. 3/4, pp. 130-138.

21. Shishkin A.I. Sushchnost, zadachi i printsipy monitoringa sotsialno-ekonomicheskikh protsessov $\mathrm{v}$ regione [The Essence, Tasks and Principles of Monitoring Socio-Economic Processes in the Region]. Ekonomika Severo-Zapada: problemy i perspektivy razvitiya, 2004, no. 1 (19), pp. 16-30.

22. Shleynikov V.I. Finansovyy kontrol i audit: ot proshlogo $\mathrm{k}$ budushchemu (filosofiya (kontury budushchego) finansovogo kontrolya v Rossii) [Financial Control and Audit: from the Past to the Future (the Philosophy (Contours of the Future) of Financial Control in Russia)]. Audit i finansovyy analiz, 2007, no. 1, pp. 6-25.

23. Shuvalova Yu.Yu. Sovershenstvovanie monitoringa sotsialno-ekonomicheskogo razvitiya regiona: avtoref. dis. ... kand. ekon. nauk [Improvement of Monitoring Social and Economic Development of the Region. Cand. econ. sci. abs. diss.]. Saint Petersburg, 2012. 21 p.

24. Ekkerson U.U. Paneli indikatorov kak instrument upravleniya: klyuchevye pokazateli effektivnosti, monitoring deyatelnosti, otsenka rezultatov [Dashboards as a Management Tool: Key Performance Indicators, Performance Monitoring, Evaluation of Results]. Moscow, 2007. 395 p.

25. Helfert E.A. Financial analysis: tools and techniques: a guide for managers. New York, McGrawHill, 2001. $485 \mathrm{p}$.

26. Wasson C.S. System analysis, design, and development: concepts, principles, and practices. Hoboken, N.J., Wiley-Interscience, 2005.818 p. 


\section{Information About the Authors}

Olga A. Lomovtseva, Doctor of Sciences (Economics), Professor, Department of Management and Marketing, Belgorod State National Research University, Pobedy St., 85, 308000 Belgorod, Russian Federation, Lomovceva@bsu.edu.ru.

Boris A. Tkhorikov, Candidate of Sciences (Sociology), Associate Professor, Head of Department of Management and Marketing, Belgorod State National Research University, Pobedy St., 85, 308000 Belgorod, Russian Federation, Tkhorikov@bsu.edu.ru.

\section{Информация об авторах}

Ольга Алексеевна Ломовцева, доктор экономических наук, профессор кафедры менеджмента и маркетинга, Белгородский государственный национальный исследовательский университет, ул. Победы, 85, 308000 г. Белгород, Российская Федерация, Lomovceva@bsu.edu.ru.

Борис Александрович Тхориков, кандидат социологических наук, доцент, заведующий кафедрой менеджмента и маркетинга, Белгородский государственный национальный исследовательский университет, ул. Победы, 85, 308000 г. Белгород, Российская Федерация, Tkhorikov@bsu.edu.ru. 